\title{
História e Relações Internacionais: o caso do Brasil
}

\author{
Paulo Fagundes Visentini \\ Professor Titular de Relações Internacionais \\ Universidade Federal do Rio Grande do Sul - UFRGS \\ paulovi@ufrgs.br
}

\begin{abstract}
Como citar este artigo: VISENTINI, Paulo. "História e Relações Internacionais: o caso do Brasil”, Intelligere, Revista de História Intelectual, nº10, pp. 46-69. 2020. Disponível em <http://revistas.usp.br/revistaintelligere>. Acesso em $\mathrm{dd} / \mathrm{mm} /$ aaaa
\end{abstract}

Resumo: Na historiografia brasileira e mundial, a História Diplomática deu lugar à História das Relações Internacionais. Todavia, ambas têm caminhado paralelamente, com periodizações próprias e dissociadas, sem dialogar apropriadamente. $\mathrm{O}$ presente artigo busca associar ambas as periodizações, posicionando o Brasil dentro da História das Relações Internacionais mundiais, desde a fase colonial até o século XXI.

Palavras-chave: Brasil; História; Relações Internacionais.

\section{History and International Relations: the case of Brazil}

Abstract: In both Brazilian and world historiography, diplomatic history gave rise to the History of International Relations. However, both are following parallel paths, with exclusive and dissociate periodizations, without stablishing an appropriate dialogue. This article tries to associate both periodizations, positioning Brazil in the global History of International Relations, from the colonial period to the 21 st Century

Keywords: Brazil; History; International Relations.

\footnotetext{
${ }^{1}$ Historiador e Professor Titular de Relações Internacionais da UFRGS, Doutor em História Econômica/USP, Pós-Doutorado em Relações Internacionais/London School of Economics e pela PUC-Rio, Coordenador do Núcleo de Estratégia e Relações Internacionais do CEGOV/UFRGS (paulovi@ufrgs.br).
} 


\section{Introdução}

A História é, erroneamente, considerada dentro do campo das Relações Internacionais (RI) como uma sub-área de aplicação, a História das Relações Internacionais. $\mathrm{Na}$ verdade, a Geografia, a Ciência Política e a História constituem o tripé basilar das RI. Aspectos sociológico-culturais, jurídicos e filosóficos se encontram inseridos dentro das três áreas. O problema é que o desenvolvimento das RI tem se baseado na predominância de teorias e modelos da Ciência Política, com limitado conhecimento geográfico e quase completo desconhecimento histórico. O Sistema Internacional e Mundial é um fenômeno histórico em sua formação e evolução.

A formação social e nacional brasileira teve sua origem na expansão europeia dos séculos XV-XVI, através da "descoberta" e colonização portuguesas. Durante quase quatro séculos a inserção internacional da região processou-se através das potências europeias, inicialmente por meio do mercantilismo português e, posteriormente, via liberalismo inglês. $\mathrm{Na}$ passagem do século XIX para o XX, contudo, o eixo da diplomacia política e econômica do Brasil se voltou para os Estados Unidos, limitando-se ao âmbito do hemisfério. Desde o início dos anos 1960, na esteira do desenvolvimento industrial, a política exterior brasileira voltou-se para a busca de novos espaços, através da mundialização e da multilateralização. Sob os efeitos da globalização, no final do século XX, o país passou a também valorizar o espaço regional latino-americano.

A História Diplomática tradicional abarcava apenas o estudo das relações oficiais entre os Estados, expressa na atuação de agentes credenciados pelos governos. No Brasil, essa tendência atingiu o ápice nas histórias diplomáticas de Hélio Vianna e Delgado de Carvalho. Essa abordagem cedeu o seu lugar à mais complexa História das Relações Internacionais, desde a afirmação dos trabalhos de Pierre Renouvin e Jean-Baptiste Duroselle, nas décadas de 1950 e 1960. No Brasil, a nova perspectiva teórica foi desenvolvida a partir dos estudos de José Honório Rodrigues, tais como Brasil e África, e Interesse Nacional e Política Externa, ambos dos anos 1960. (RODRIGUES,1964); (RODRIGUES, 1966) 
A política exterior envolve aspectos mais determinados dentro do conjunto das Relações Internacionais. Ela enfoca a orientação governamental de determinado Estado a propósito de determinados governos e/ou Estados, ou ainda regiões, situações e estruturas, em conjunturas específicas. A interação, conflitiva ou cooperativa, das políticas externas deve ser considerada como parte de um sistema mundial, constituindo então em seu conjunto a política internacional.

Durante a fase colonial, o Brasil encontrava-se integrado ao mercantilismo português. Com o advento do processo de emancipação, nossa dependência assimétrica transferiu-se para a órbita do livre comércio hegemonizado pela Inglaterra. Paralelamente, acentuou-se outra dimensão das Relações Internacionais do Brasil: a dos problemas regionais vinculados à construção do espaço geopolítico e nacional brasileiro, também enfocada como "questão de fronteiras". Nesse contexto, a rivalidade com a Argentina fazia parte de uma relação simétrica, herdada dos antagonismos coloniais, a qual caracterizou-se como um campo de relativa autonomia para o exercício de nossa diplomacia.

A dupla problemática da subordinação unilateral ao capitalismo mediterrânico e norte-atlântico e da construção do espaço nacional, constituiu a primeira fase das nossas relações exteriores, a qual estendeu-se por quatro séculos. Durante o século XIX, esse processo configurou-se como uma unilateralidade sob hegemonia inglesa, segundo conceito de Silva e Gonçalves (1964). Já ao longo das últimas décadas desse século, afirma-se gradativamente a influência norte-americana, prenunciando o advento de uma nova fase.

A unilateralidade durante a hegemonia norte-americana representará um novo período das Relações Internacionais do Brasil. Nela, será concluído o traçado das fronteiras, o país voltar-se-á para um processo de inserção hemisférica e terá início uma vinculação mais estreita da política externa com o desenvolvimento econômico. A gestão Rio Branco (1902-12) representou um momento paradigmático dessa fase, pois concluiu a demarcação das fronteiras contestadas e estruturou a chamada aliança não escrita (segundo a clássica expressão de Bradford Burns) com os Estados Unidos da América. Coube a Vargas e aos governos populistas dos anos 1950, por sua vez, a vinculação 
estratégica da política exterior às necessidades do processo de desenvolvimento econômico, fenômeno que Amado Cervo denominou de política externa para o desenvolvimento.

Durante todo esse período, que se estende até o fim da década de 1950, as relações exteriores do Brasil voltaram-se prioritariamente para os EUA, em busca do status de aliado privilegiado. $\mathrm{Na}$ medida, entretanto, em que esta relação se mostrava insuficiente como apoio ao desenvolvimento industrial, incrementado desde os anos 1930, a política externa brasileira viu-se na contingência de alterar o seu perfil. A autonomia na dependência (MOURA, 1980), que Vargas explorou às vésperas da Segunda Guerra Mundial, e o nacionalismo dos governos populistas dos anos 1950 representaram uma estratégia de barganha frente a Washington. Essa barganha visava redefinir os laços de dependência face aos EUA, de forma a obter apoio ao desenvolvimento industrial brasileiro.

A falta de uma resposta positiva por parte dos Estados Unidos convenceu lideranças brasileiras da época da necessidade de ampliar os vínculos internacionais do Brasil. Fazia-se necessário atuar num plano mundial, escapando à dependência hemisférica face aos EUA, não obstante isso permitisse ampliar a própria barganha com esse país. Embora esse processo começasse a emergir desde o segundo governo Vargas, foi com a Política Externa Independente de Jânio Quadros e João Goulart, entre 1961 e 1964, que ela se configurou de forma explícita em nossa agenda diplomática.

Inicia-se então o terceiro grande período das relações exteriores brasileiras, o da multilateralidade na fase da crise de hegemonia no sistema mundial, que se estende até a atualidade. Aprofundou-se a vinculação da política exterior com a estratégia de desenvolvimento econômico, ao mesmo tempo em que se diversificavam os nossos parceiros internacionais. Apesar da manutenção de um eixo vertical Norte-Sul, em particular as relações com os EUA, a diplomacia brasileira passou a atuar também num eixo horizontal Sul-Sul e num eixo diagonal Sul-Leste (relações com o Terceiro Mundo e com os países socialistas, respectivamente). Isso tornou-se possível tanto pelas necessidades do desenvolvimento brasileiro quanto pelo advento de um sistema mundial de hegemonias em crescente desgaste. 
Embora os três anos iniciais do regime militar tenham sido caracterizados por um retrocesso ao alinhamento automático com os Estados Unidos e o refluxo a uma diplomacia de âmbito hemisférico, e a década de 1964-74 fosse marcada pelas "fronteiras ideológicas", a multilateralidade das relações exteriores e a busca do "interesse nacional do desenvolvimento" continuaram a aprofundar-se. Os novos interesses internos então configurados, bem como as alterações do cenário internacional após o primeiro choque petrolífero permitiram ao governo Geisel ampliar esse processo, através do "Pragmatismo Responsável e Ecumênico". Nem mesmo o fim do regime militar em 1985 interrompeu esta estratégia diplomática, que prosseguiu até 1990.

O Brasil praticava, então, uma política exterior com o perfil de uma potência média e de abrangência planetária. As vigorosas alterações do cenário mundial, na passagem dos anos 1980 aos 1990, e a implantação de um modelo inspirado no neoliberalismo com o governo Collor, entretanto, configuram uma crise no processo de multilateralização, a qual ainda não foi superada. Nesse contexto, emerge a discussão acadêmica e política da inserção do Brasil no Globalismo Neoliberal pós-Guerra-Fria.

\section{A unilateralidade durante a colonização portuguesa e a hegemonia inglesa}

No tocante à diplomacia brasileira, é necessário balizar um marco fundamental da política externa: seu caráter estrutural e organicamente dependente, ainda que logrando relativa autonomia conjuntural e regional. Segundo Silva e Gonçalves (2009, p. 25):

\footnotetext{
A nossa própria história geral é, por hipótese, um capítulo da totalidade da história do capitalismo ocidental, norte-atlânticomediterrâneo, em gradativa construção e reconstrução, na qual a totalidade da formação brasileira se colocou, historicamente, numa posição subordinada que cumpre sempre reavaliar e superar. Isto se reflete, evidentemente, nas Relações Internacionais.
}

A primeira fase da política externa brasileira abarca desde o Tratado de Tordesilhas até o início da gestão do Chanceler Barão de Rio Branco, no início do século XX. Como se pode ver, a existência legal do Brasil (1494) antecede sua existência real (1500). Esse longo período caracteriza-se pela problemática 
dominante da definição do espaço territorial, um verdadeiro imperialismo geográfico luso-brasileiro (espécie de "destino manifesto"), e pela dependência primeiramente em relação ao mercantilismo português e, posteriormente, ao capitalismo industrial inglês em expansão, de viés liberal-concorrencial. Além dos vínculos com a Europa, a América Portuguesa também manteve relações expressivas com a África, onde eram apresados os escravos que constituíam a mão de obra das plantations. Assim, a História Econômica elaborou o conceito de triângulo comercial atlântico. De outra parte, durante a fase colonial os conflitos europeus repercutiam diretamente no Brasil, especialmente no tocante às guerras platinas.

O ciclo do ouro estabeleceu no Brasil do século XVIII os fundamentos de uma divisão da produção entre as diversas regiões, articulando-as entre si e acentuando o conflito de interesses com a metrópole. A crise do Antigo Sistema Colonial, por seu turno, enfraquecia o mercantilismo português, subordinando-se ao capitalismo inglês. Esse fenômeno acelerou-se na passagem do século XVIII ao XIX, com a Revolução Francesa.

As guerras napoleônicas representaram o apogeu do confronto entre dois modelos (e dois estágios) de capitalismo, o inglês e o francês, na disputa pela hegemonia mundial. Enquanto a França afirmava-se na Europa, através do Bloqueio Continental, a Inglaterra consolidava o seu domínio sobre os mares e sobre o mundo colonial, isto é, sobre o mercado global. Nesse quadro, ocorreu a invasão de Portugal por Napoleão, e a vinda da Corte e da administração lusitanas para o Rio de Janeiro, sob a proteção da armada britânica em 1808. A metrópole internalizava-se no Brasil, enquanto os portos eram abertos ao livre comércio inglês.

Com o fim da guerra na Europa e a restauração conservadora do Congresso de Viena, a situação altera-se. A constelação de Estados conservadores, da qual Portugal fazia parte, apostava num movimento recolonizador. Mas a dinastia dos Bragança encontrava-se no Brasil, na América em processo de emancipação, e a Inglaterra e os Estados Unidos opunham-se a qualquer forma de reação colonialista, além de apoiar o movimento de independência das possessões ibéricas. O dilema bragantino 
logo teve de ser resolvido. A Revolução Constitucionalista do Porto de 1820 obrigou D. João VI a retornar a Portugal.

A conjuntura contraditória entre o reacionarismo na Europa, por um lado, e Revolução e livre comércio na América Latina, por outro, levaram os Bragança a uma solução ousada: dividir os domínios da família em dois, o Brasil de um lado do Atlântico e o Império Português de outro (1822). O acordo entre os dois ramos da dinastia foi avalizado pela Inglaterra (através do Tratado Luso Brasileiro de 1825), em troca de um acordo de livre comércio (renovação do de 1810) e o compromisso brasileiro de extinguir o tráfico negreiro. Assim, o I Reinado manteve a diplomacia bragantina e a acentuada continuidade com a etapa anterior. É importante destacar que o Brasil, por sua estrutura monárquica e escravista, procurava capitalizar o papel de Europa nos Trópicos, antagonizando-se com as Repúblicas formadas na Hispano-América. O Prata, onde prosseguiam as rivalidades entre Brasil e Argentina, bem como as intromissões da Inglaterra e da França, representou a principal área de atrito entre o Império e os demais países do continente. É nesse espaço que o Brasil defenderá seus interesses com relativa autonomia.

Com a renúncia de D. Pedro I e a instalação da Regência em 1831, iniciam-se lutas em torno da hegemonia político-econômica entre as diversas regiões do país. Isso implicou em um refluxo da política externa, com questões internas adquirindo primazia, e no Prata o Brasil adotava a atitude de neutralidade paciente. Apesar da momentânea e aparente perda de importância da diplomacia, é justo nessa etapa que se configura uma política externa propriamente brasileira, ainda que marcada pela herança bragantina. O Conselho de Estado constituiu, então, o primeiro núcleo formulador da diplomacia nacional.

A década de 1840 foi marcada pela implantação do II Reinado e pela consolidação política, econômica e diplomática do novo Estado. A partir daí abre-se uma fase de reações contra as pressões inglesas pela renovação do acordo de livre-comércio. Em 1844 são implantadas as Tarifas Alves Branco, de caráter protecionista, provocando a reação de Londres através do Bill Aberdeen, o qual visava impedir o tráfico de escravos. Desta forma, a extinção 
do sistema dos tratados permitiu a criação de condições para a articulação de um projeto de política externa, apesar da persistência de uma relação de dependência assimétrica com a Inglaterra. Na década de 1850 inicia-se o apogeu da formação social representada pela monarquia, o que se refletiu na política externa. Os desacordos com a Inglaterra atingem o paroxismo com a questão Christie e a ruptura das relações diplomáticas entre o Rio de Janeiro e Londres, de 1863 a 1865. Obviamente, isso não significou a ruptura das relações comerciais e financeiras, as quais permaneceram intensas (CERVO; BUENO, 1992).

Outra dimensão fortalecida nessa época foi a política de força em relação ao Prata. Os interesses diplomáticos, econômicos e políticos levaram o Brasil a desencadear uma série de intervenções na região: Uruguai, 1851; Argentina, 1852; Uruguai, 1855-56; e, finalmente, Uruguai, 1864, que já vincula-se ao desencadeamento da Guerra da Tríplice Aliança (Brasil, Argentina e Uruguai) contra o Paraguai - 1865-70. O objetivo do Sistema do Império no Prata consistia na defesa dos interesses econômicos, livre-navegação, apoio aos colorados no Uruguai, mas, sobretudo, visava obstaculizar a construção de uma Argentina forte, capaz de rivalizar com o Brasil. Esse último princípio também foi aplicado ao Paraguai de Solano Lopez.

Após a guerra do Paraguai, de onde o Brasil retira-se em 1876, altera-se profundamente a situação nacional, regional e mundial. Com a transição do escravismo ao trabalho assalariado, entre outros fatores, a monarquia entra em contínuo declínio, o que traz consequências negativas para a política externa. No plano regional, a Argentina emerge fortalecida: em plena expansão econômica, logo ultrapassando o Brasil em dinamismo. Por outro lado, com a expansão das ferrovias brasileiras ao curso médio dos rios Uruguai, Paraguai e Paraná, a Bacia do Prata perde o interesse estratégico para a diplomacia do país.

A arrancada argentina, por sua vez, vincula-se também à rearticulação da economia mundial, com o desencadeamento da Segunda Revolução Industrial. Graças a ela, processava-se uma reorientação profunda nas relações entre o centro e a periferia do sistema mundial. A Argentina levava vantagens nesse 
processo, recebendo capitais, imigrantes e novas tecnologias para adequar a estrutura produtiva do país às novas necessidades da Europa industrial.

Neste contexto, apesar de evoluir mais lentamente, o Brasil via valorizarem-se outros produtos e regiões, bem como configurarem-se novos parceiros externos. A economia primário-exportadora, orientada ao crescimento para fora, precisava modernizar-se e atender às novas demandas. A cafeicultura, progressivamente processada por trabalhadores assalariados, bem como a borracha explorada na Amazônia, destinavam-se cada vez mais aos mercados dos emergentes Estados Unidos da América. Reflexo dessa aproximação foi, inicialmente, o convite do Presidente Grant para que D. Pedro II abrisse a Centennial Exposition em 1876 na Filadélfia, e, posteriormente, a insistência norte-americana para que o Brasil apoiasse a criação de um Zolverein nas Américas (União Aduaneira Americana, 1886). Outra questão que marcou a política exterior brasileira na fase de transição da Monarquia à República, apesar do relativo retraimento diplomático, foi o esforço por continuar defendendo as fronteiras contestadas, processo que só culminará com a gestão Rio Branco, já no início do século XX.

Após 1876, envolvido com seus problemas internos, o Brasil conheceu um refluxo em sua política externa. Igualmente, a proclamação da República em 1889 faz com que a ênfase da ação governamental estivesse voltada aos aspectos internos. Apesar disso, em função também da ascensão da Argentina neste período, a diplomacia brasileira começa a voltar-se para os Estados Unidos, que, por seu turno, projetava sua economia para fora, especialmente em direção à América Latina.

Apesar das transformações que se operaram ao longo do século XIX, se afirmavam alguns elementos estruturais da diplomacia brasileira. O primeiro consiste na condição dependente de "país novo e atrasado", graças à subordinação de uma economia primário-exportadora aos centros internacionais (na época, a Inglaterra hegemônica). Nesse plano, configurava-se uma relação político-econômica assimétrica, pois o Brasil se encontrava em posição de flagrante inferioridade. Entretanto, num segundo plano, o país conseguia 
desenvolver uma diplomacia relativamente autônoma, na forma de uma relação simétrica de poder, representado então pela política no Prata.

É preciso considerar, também, que em certas conjunturas o Brasil desafiava, ainda que de forma parcial, certos aspectos da hegemonia inglesa. A defesa de determinados interesses socioeconômicos da elite brasileira fazia a diplomacia nacional buscar certa margem de manobra, perfilando-se igualmente aqui uma relativa autonomia. Mas também é necessário observar que esta mesma elite sofria de uma espécie de "síndrome do escravismo". Para a manutenção da hierarquia social no país, esse grupo não hesitava em subordinar-se a interesses estrangeiros, assumindo conscientemente a posição de sócio menor. Neste sentido, o potencial diplomático do país resultará, então, bastante inferior ao volume de sua população, recursos econômicos, naturais e territoriais. Sempre haverá um "perigo interno" a ser priorizado. Esse elemento persistirá, mesmo após a abolição.

Finalmente, é importante salientar outro elemento duradouro da política internacional do Brasil. Trata-se da tendência em posicionar-se como rival dos Estados hispano-americanos. A política hegemonista em relação aos vizinhos, a ambição à liderança regional, o temor a determinadas configurações sociais reformistas do Republicanismo e do jacobinismo hispano-americanos, e a oposição às tendências integradoras do panamericanismo de orientação bolivariana fizeram muitas vezes o Brasil associar-se às grandes potências contra os países latino-americanos. Assim, o Brasil será considerado, e considerará a si próprio, como um "país diferente" do restante da América Latina.

\section{A unilateralidade sob hegemonia norte-americana}

A segunda fase da política exterior brasileira abrange desde a gestão Rio Branco (1902-12) até o fim do governo Juscelino Kubitschek (1956-61), e tem como temática principal as relações hemisféricas. A inserção brasileira no sistema interamericano nesta fase caracteriza-se por uma "aliança não-escrita" com os EUA, país em relação ao qual nossa economia passou a depender prioritariamente. Durante este período, variaram as formas dessa "aliança": "de acordo, sempre que possível", "nobre emulação"; "parceiros prediletos" ou 
"satélites privilegiados". Entretanto, não se duvidava que todas essas nuances se inseriram em uma mesma perspectiva, a de que a "aliança" com Washington constituía a espinha dorsal da política exterior brasileira.

Durante a primeira metade do século XX, como foi ressaltado, a diplomacia brasileira teve como tendência predominante a inserção no contexto hemisférico, onde o eixo principal era a relação com os Estados Unidos. Não se tratava apenas da dependência face aos EUA, mas do fato de o Brasil centrar sua política externa no estreitamento das relações com Washington, dentro da perspectiva da "aliança não escrita", concebida durante a gestão Rio Branco. A dependência, enquanto tal, prosseguiu depois desta fase, mas a tônica não era mais essencialmente a busca de uma aproximação privilegiada com os Estados Unidos. Ao longo desta fase, houve momentos de busca de uma relativa "autonomia na dependência", ou de barganha para a defesa de certos interesses brasileiros, como durante a gestão Rio Branco e o primeiro governo Vargas.

A gestão Rio Branco (1902-1912) foi marcante, uma vez que nela foram demarcadas vantajosamente as fronteiras amazônicas. Durante o auge do ciclo da borracha, o conflito do Acre evidenciou a determinação e a continuidade da política exterior brasileira. Além disso, Rio Branco desenvolveu uma política de defesa dos interesses nacionais, numa época de dificuldades devidas ao reordenamento mundial. A aliança com os EUA, a par da subordinação evidente, assinalava a busca de uma estratégia de barganha, com vistas ao fortalecimento da posição internacional do Brasil.

O restante da República Velha (1912-1930) e o mandato do presidente Dutra caracterizam-se, em oposição, por uma dependência relativamente passiva frente aos EUA. Após a morte de Rio Branco, e sobretudo com a Primeira Guerra Mundial, os interesses norte-americanos afirmaram-se de forma assimétrica. Nos anos 1920, o desgaste da República cafeeira fez inclusive com que a diplomacia brasileira refluísse. A crise de 1929, enfim, desarticulou ainda mais a capacidade do país em formular uma diplomacia positiva. 
Todavia, devido à ascensão do projeto varguista de desenvolvimento, o período 1930-45 pautou-se por uma tentativa consciente de tirar proveito da conjuntura internacional e da redefinição da economia brasileira, através da utilização da política externa como instrumento estratégico para lograr a industrialização do país. É necessário ressaltar, entretanto, que o estágio embrionário do desenvolvimento brasileiro e as escassas possibilidades oferecidas pelo contexto internacional, a longo e médio prazos, limitaram o alcance desta inovação introduzida por Vargas. A diplomacia pendular do Brasil, entre Washington e Berlim, durante a preparação da Segunda Guerra Mundial buscava, em essência, reativar a velha "aliança privilegiada" com os EUA, inovando-a com outras formas de cooperação econômica. Em suma, Vargas ensaiava uma nova política externa em uma situação ainda dominada por velhas estruturas, de alcance regional.

A derrubada do ditador estadonovista e o caráter da política externa do governo Dutra evidenciaram esses elementos limitativos. Além do mais, a tendência a formas mais ou menos passivas de uma acomodação submissa aos EUA ainda se fariam sentir entre 1945 e 1964, especialmente durante o governo Dutra. Porém, a volta de Vargas ao poder vai significar uma importante mudança. É inegável que ainda iria persistir em larga medida a ilusão de que o Brasil poderia, através de uma barganha nacionalista, voltar a lograr estabelecer vínculos privilegiados com os EUA. A ilusão persistiu até o final do governo Kubitschek. Mas a situação nos anos 1950 era diferente. O desenvolvimento econômico e a progressiva afirmação de um novo perfil sociopolítico da sociedade brasileira impunham novas demandas à política exterior.

A década de 1950 abria-se com o avanço da urbanização e da industrialização, a afirmação de um empresariado industrial, de segmentos médios urbanos, de uma jovem classe operária e outros trabalhadores urbanos e rurais. O sistema político tinha de responder à crescente participação popular, enquanto as contradições da sociedade brasileira constituíam um terreno fértil para os conflitos sociais. Assim, Vargas viu-se na contingência de retomar o projeto de desenvolvimento industrial por substituição de importações, incrementando a indústria de base. O setor externo da economia 
jogava, então, um papel fundamental para a obtenção de capitais e tecnologias, que só poderiam ser obtidas via cooperação econômica com a potência então hegemônica, os EUA. Mas no quadro da Guerra Fria o espaço de manobra era limitado para atrair a atenção americana (BANDEIRA, 1976).

Assim, Vargas procura implementar uma barganha nacionalista, a qual consistia em apoiar Washington no plano político-estratégico da Guerra Fria, em troca da ajuda ao desenvolvimento econômico brasileiro. Esta política, ao mesmo tempo, fortaleceria a posição interna do governo, obtendo apoio de diferentes forças políticas domésticas. As contradições internas cada vez mais pronunciadas e os magros resultados obtidos no plano externo atingiram um ponto grave, a partir de 1953, com a eleição do Republicano Eisenhower. Neste momento, Vargas viu-se na contingência de aprofundar sua barganha diplomática, visando a reverter um quadro crescentemente adverso. $\mathrm{O}$ problema, contudo, era que o cenário internacional não oferecia muitas alternativas, pois os países socialistas ainda eram considerados "inimigos", a Europa ocidental e o Japão mal concluíam a reconstrução econômica, enquanto o Terceiro Mundo recém despertava como realidade política devido ao embrionário estágio da descolonização. A América Latina, por seu turno, encontrava-se sob forte pressão dos EUA, além de politicamente bastante dividida.

De qualquer forma, Vargas procurou tirar proveito dos limitados espaços, além de tentar criar outros. Todavia, mesmo este esboço de multilateralização, o qual visava mais a barganha com os EUA do que uma nova forma de inserção no plano mundial, viu-se obstaculizado pelos acirrados conflitos internos, onde a oposição articulava-se diretamente com Washington, isolando o governo e levando o presidente ao suicídio em 1954.

A derrubada do governo Vargas e a reação conservadora que se seguiu, tanto no plano interno como, sobretudo, externo evidenciaram que a barganha nacionalista havia se tornado uma política incômoda para o status quo internacional hegemonizado pelos Estados Unidos. A tentativa precoce de promover uma diplomacia não linearmente subordinada a Washington apoiava-se em fatores objetivos em desenvolvimento, e não apenas na vontade 
política de um líder populista. Por isso significou o esboço de uma nova política externa brasileira, que conhecerá seu amadurecimento com a Política Externa Independente.

Entre 1954 e 1958, essa linha política conheceu um sério retrocesso, e houve um autêntico hiato com relação às tendências marcantes do período. A gestão Café Filho caracterizou-se pela abertura econômica absoluta ao capitalismo internacional e pelo retorno do alinhamento automático em relação à diplomacia americana, tal como no governo Dutra. $O$ projeto de desenvolvimento foi momentaneamente abandonado em nome de um liberalismo econômico extremado, enquanto a barganha nacionalista desaparecia das palavras e atitudes do governo. Tratava-se da afirmação da diplomacia da Escola Superior de Guerra e sua concepção de segurança e desenvolvimento.

Com a ascensão de Kubitschek ao poder, em 1956, a situação altera-se em certo sentido. O Brasil continua calcando sua política externa no alinhamento automático com relação aos EUA, concentrando-se na diplomacia hemisférica. Também prossegue a abertura ampla da economia ao capital internacional. Contudo, JK retomou o projeto de industrialização, só que agora calcado no setor de bens de consumo durável para as classes de média e elevada renda. Assim, Kubitschek conseguia conjunturalmente um espaço em que se harmonizavam os interesses da potência hegemônica e de um projeto de industrialização alterado. É necessário salientar, todavia, que tal política foi possível, entre outros fatores, pelo retorno pleno da Europa ocidental às relações econômicas internacionais, fornecendo alternativas comerciais e financeiras ao Brasil, sem confrontação com Washington.

Esse hiato, com suas duas fases distintas, no entanto, encerra-se em 1958, com a retomada da barganha nacionalista por JK, em termos muito semelhantes à de Vargas. A crise dos milagrosos "50 anos em 5" e determinadas alterações internacionais, como a criação da Comunidade Econômica Europeia, a reeleição de Eisenhower num quadro de crise e descontentamento latino-americano, bem como as pressões do FMI, levaram o governo a retomar uma ativa barganha nacionalista através da Operação Pan- 
americana (OPA). Esta objetivava atrair a atenção dos EUA para a América Latina e obter maiores créditos nos marcos do sistema interamericano, comprometendo a Casa Branca num programa multilateral de desenvolvimento econômico de largo alcance.

A OPA pretendia não só incrementar os investimentos nas regiões economicamente atrasadas do continente, compensando a escassez de capitais internos, mas também promover a assistência técnica para melhorar a produtividade e garantir os investimentos realizados, proteger os preços dos produtos primários exportados pela América Latina, bem como ampliar os recursos e liberalizar os estatutos das organizações financeiras internacionais. Ao contrário da Aliança para o Progresso, que priorizava os capitais privados e as relações bilaterais, a OPA enfatizava a utilização de capitais públicos e a multilateralização das relações interamericanas. Paralelamente, JK buscou expandir a barganha para a área socialista e terceiro-mundista, mas de forma extremamente acanhada. A economia brasileira internacionalizava-se progressivamente, e os conflitos sociais exacerbavam-se, enquanto as repercussões da Revolução Cubana criavam problemas adicionais. Não podendo agir além do que lhe permitiam suas bases de sustentação política, a diplomacia de JK permanecerá no meio do caminho, empurrando para seus sucessores decisões que não podia ou não estava disposta a tomar.

\section{A multilateralidade durante a détente e a tendência à multipolaridade}

A terceira fase da política externa brasileira abarca o período que se inicia com a Política Externa Independente e vem até nossos dias. As caraterísticas básicas do período são a multilateralização das relações exteriores e os componentes ideológicos nacionalistas, onde o alinhamento automático em relação aos EUA passa a ser questionado. Ainda que a dependência face ao Norte industrializado persista, o aprofundamento do caráter multinacional do capitalismo permite a introdução de elementos novos. Conforme Silva e Gonçalves (2009, p. 31): 


\begin{abstract}
Até este terceiro 'momento' o eixo Norte-Sul dominava as diretrizes que formulavam a nossa política externa, configurandose uma dependência tão forte e exclusiva ao mundo Norteatlântico nas Relações Internacionais, que elas ficaram marcadas pelo traço da unilateralidade. Neste terceiro 'momento', extremamente polêmico e diversificado nas nuanças conjunturais, começamos a praticar, no possível, a multilateralidade. Vislumbrase a primeira oportunidade de horizontalizar (eixo Sul-Sul) ou de diagonalizar (eixo Sul-Leste) nossa política externa, mas isto sem negar totalmente a verticalização (eixo Norte-Sul). Com a horizontalização passaríamos a valorizar mais as nossas relações com a América Latina e a África. (...) Ora, para que ocorra este reposicionamento nos sistemas interamericano e mundial, é preciso discutir a liderança dos EUA.
\end{abstract}

Em 1961 Jânio Quadros e seu Chanceler, Afonso Arinos, lançaram a Politica Externa Independente (PEI), que tinha como princípios a expansão das exportações brasileiras para qualquer país, inclusive os socialistas, a defesa do direito internacional, da autodeterminação e a não-intervenção nos assuntos internos de outras nações, uma política de paz, desarmamento e coexistência pacífica, apoio à descolonização completa de todos os territórios ainda dependentes e a formulação autônoma de planos nacionais de desenvolvimento e de encaminhamento da ajuda externa. A raiz de tal diplomacia encontrava-se nas necessidades do desenvolvimento brasileiro, que sinalizavam para a mundialização e autonomia da política externa face aos EUA, que não contribuíam economicamente, como desejavam as elites em troca de seu alinhamento com Washington.

Tentando agradar o capital internacional pelo programa de austeridade, os setores populares pela reforma e a pequena-burguesia através da onda moralizadora com que enfrentava os escândalos de corrupção, Quadros ia ampliando o descontentamento e a oposição a seu governo. A direita e os EUA reprovavam sua política externa, enquanto a esquerda e os segmentos populares criticavam duramente o programa econômico-financeiro. Enquanto o presidente, com seu estilo personalista, isolava-se das diversas forças políticas, os atritos se multiplicavam. As iniciativas para estabelecer relações diplomáticas com os países socialistas (URSS e leste europeu), o apoio à luta pela independência das colônias africanas de Portugal, a defesa da nãoingerência em relação à Revolução Cubana, a aproximação e cooperação com a Argentina (Tratado de Uruguaiana) e a retórica nacionalista e terceiro-mundista descontentaram os EUA e as Forças Armadas. 
Marcado pela suspeição ideológica, o governo Goulart será caracterizado pela instabilidade e imobilismo. No plano diplomático, o novo Chanceler, San Tiago Dantas, aprofundou a PEI como "defesa do interesse nacional", voltada ao desenvolvimento, à soberania e, explicitamente, à reforma social. Apesar de não conseguir implementar-se plenamente, a Política Externa Independente gerou atritos crescentes com os EUA, devido à recusa brasileira quanto à expulsão de Cuba da OEA (Punta del Este, 1962), à política de encampação de empresas estrangeiras por Brizola e outros governadores e o restabelecimento de relações com a URSS em 1962. Além dos caminhos e descaminhos da política do regime populista preocuparem a Casa Branca, a PEI, especialmente, encontrava-se sob a mira do governo norte-americano.

Com o golpe de 1964 tem início o regime militar e uma nova fase da política externa, ainda que marcada por traços de continuidade. O governo Castelo Branco representou um verdadeiro recuo, abandonando o terceiromundismo, o multilateralismo e a dimensão mundial da Política Externa Independente, regredindo para uma aliança automática com os EUA e para uma diplomacia de âmbito hemisférico e bilateral. O que embasava tal política era a geopolítica típica da Guerra Fria, teorizada pela Escola Superior de Guerra, com seu discurso centrado nas fronteiras ideológicas e no perigo comunista. Em troca da subordinação a Washington e do abandono da diplomacia desenvolvimentista, o Brasil esperava receber apoio econômico. O Chanceler Juracy Magalhães chegou a afirmar que "o que é bom para os EUA é bom para o Brasil". Como prova de lealdade ao "grande irmão do norte", o Brasil rompeu relações com Cuba em maio de 1964 e enviou tropas à República Dominicana em junho de 1965 sob a bandeira da OEA, onde também apoiava os EUA na tentativa de constituir uma Força Interamericana de Defesa.

No governo Costa e Silva, as Relações Internacionais representaram uma ruptura em relação ao governo anterior, contrariando frontalmente Washington. A Diplomacia da Prosperidade, do Chanceler Magalhães Pinto, enquanto política externa voltada à autonomia e ao desenvolvimento, assemelhava-se muito à PEI, embora sem fazer referência à reforma social. Ressaltava que a détente entre os EUA e a URSS fazia emergir o antagonismo 
Norte-Sul, e em função disso definia-se como nação do Terceiro Mundo e propugnava uma aliança com ele, visando a alterar as regras injustas do sistema internacional. Tal foi a tônica na II UNCTAD, onde o discurso do representante brasileiro valeu-lhe sua indicação para o recém criado Grupo dos 77, bem como na recusa em assinar o Tratado de Não-Proliferação Nuclear (TNP).

$\mathrm{Na}$ análise da política externa do regime militar é possível identificar fases bem definidas, com características próprias, apesar da existência de diversidades internas e de determinados traços comuns entre elas. A primeira fase, o governo Castelo Branco (1964-1967), constituiu um período atípico, com alinhamento automático face aos Estados Unidos, formalmente dentro da concepção de fronteiras ideológicas da Doutrina de Segurança Nacional antiesquerdista. Houve um nítido refluxo diplomático para o âmbito hemisférico, recuando das iniciativas esboçadas pela Política Externa Independente, com a primazia da ordem interna e saneamento econômico nos moldes do FMI. Durante esta fase foi dominante a concepção "liberal-imperialista", calcada no princípio de uma diplomacia interdependente (ou dependente). Contudo, é preciso reconhecer que o alinhamento brasileiro foi menos profundo do que se pode pensar, pois muito da subserviência externa foi resultante de problemas internos. Durante a "correção de rumos" de Castelo Branco, igualmente estavam sendo lançadas as bases de um novo ciclo de desenvolvimento. Portanto, muito das características de sua política externa podem ter sido conjunturais.

A segunda fase foi constituída pelos governos Costa e Silva e Médici (1967-1974), caracterizando-se pelo retorno a uma diplomacia voltada ao “interesse nacional" do desenvolvimento, embora ainda marcada por um discurso aparentemente voltado às fronteiras ideológicas. Este último aspecto deveu-se, sobretudo, a elementos de política interna, como os confrontos com setores de oposição e, inclusive, luta armada. Consistia, pois, uma forma de legitimação política interna. Iniciando com uma série de confrontos com a Casa Branca (governo Costa e Silva), houve posteriormente uma relativa margem de iniciativa autônoma nas relações com os EUA, mas ainda situadas no âmbito regional. A conjuntura interna, marcada pela luta contra os grupos 
de esquerda, fez do Brasil um "problema" e permitiu certa convergência com Washington, ao mesmo tempo em que o "milagre econômico" era impulsionado. Esta aliança com autonomia foi também possível devido à nova estratégia americana da administração Nixon-Kissinger, apoiada em aliados regionais, delegando-lhes papel de "potência média".

A terceira fase abrangeu os governos Geisel e Figueiredo (1974-1985). O Pragmatismo Responsável retomou as linhas gerais da PEI e, embora adotasse uma postura menos politizada e mais conservadora (ausência de referência a reformas sociais internas), avançou muito mais em termos práticos. Trata-se do apogeu da multilateralização e da mundialização da política externa brasileira. A redemocratização pouco viria a alterar a linha diplomática implantada por Geisel, embora a segunda metade dos anos 80 tenha presenciado a afirmação de uma conjuntura internacional adversa, que desembocará na crise do multilateralismo a partir de 1990. Nesta terceira fase, bem como na segunda, prevaleceu a concepção "nacional-autoritária", de viés autonomista e desenvolvimentista.

A política externa do período, salvo o hiato de Castelo Branco, constitui como um instrumento de apoio ao desenvolvimento econômico industrial e da construção do status de potência média, representando o ponto alto de uma estratégia iniciada com Vargas, mas cujas origens mais remotas encontram-se na ideologia tenentista. Tal política, ao longo do regime militar, visou a maior autonomia na cena internacional, produzindo-se uma crescente multilateralização e mundialização, de dimensão tanto econômica como política. Neste processo, o país necessitava exportar produtos primários de colocação cada vez mais difícil no mercado mundial, e para tanto as relações com as Europas capitalista e socialista, com a China Popular e com o Japão foram particularmente importantes.

Mas a recente industrialização tornava necessário buscar mercados também para os produtos manufaturados e serviços, e para tanto as relações com a América Latina, África, Oriente Médio e Ásia foram decisivas. Contudo, o país necessitava também importar capital, tecnologia e máquinas, fazendo-se necessário manter boas relações com o Norte capitalista, especialmente com os 
pólos emergentes europeu e japonês, mas também com o Campo Soviético. Com o primeiro choque petrolífero, também a importação de petróleo tornouse uma questão estratégica, implicando em estreitamento de relações com os países produtores, especialmente do Oriente Médio.

A utilização da política externa como instrumento de desenvolvimento, aliada às consequências do desgaste das hegemonias no sistema mundial, configuram a necessidade de redefinir as relações com os EUA, imprimindo maior autonomia à diplomacia brasileira frente ao "aliado privilegiado". Para escapar à acentuada dependência frente aos EUA e para barganhar termos mais favoráveis para essa relação, o Brasil ampliou sua diplomacia para outros pólos capitalistas (Europa Ocidental e Japão), aprofundou sua atuação nas Organizações Internacionais e buscou estreitar ou estabelecer vínculos com o Terceiro Mundo e com o mundo socialista. Assim, a verticalidade Norte-Sul passou a coexistir com a horizontalidade Sul-Sul e a diagonal Sul-Leste. Era o apogeu da multilateralização. Ultrapassando a dimensão de mero campo de barganha, a multilateralidade conduziu efetivamente à mundialização da diplomacia brasileira, introduzindo mudanças qualitativas. Os vínculos com alguns países socialistas, com a China Popular e com países-chave do Oriente Próximo, constituíram relações autônomas e equitativas entre potências de porte médio, contrariando pressupostos do sistema mundial sob hegemonia do Norte industrial (VISENTINI, 2020).

Apesar do inegável avanço que esta política representou, ela ficou aquém de suas possibilidades, considerando-se as brechas existentes no sistema internacional de então e as potencialidades político-diplomáticas do país. Acreditamos que tal "timidez" deveu-se principalmente às decorrências de uma estrutura social profundamente excludente, o que limitou e entorpeceu a ação internacional do país. Aliás, o adjetivo "responsável" agregado ao pragmatismo, também pode ser interpretado como um elemento de política interna conservadora (modernização econômica sem reforma social), ao contrário da Política Externa Independente, que teria sido "irresponsável” por associar a diplomacia autônoma a mudanças sociais domésticas. Mais ainda, muito da mobilização externa de recursos deveu-se à tentativa de manter uma 
Pax conservadora internamente. Dialeticamente, era preciso ser ousado externamente para conservar internamente.

Por outro lado, o elevado grau de internacionalização da economia brasileira fez com que muitos setores empresariais, governamentais e políticos preferissem apostar em vínculos dependentes, inclusive como condição para manter intocadas as estruturas sociais internas. Além disso, quando as dificuldades externas cresceram na passagem dos anos 1970 aos 1980, muitos tentaram negociar uma acomodação com o hegêmona, em lugar de prosseguir numa estratégia autonomista cada vez mais onerosa.

Contudo, é forçoso reconhecer que o paradigma das relações exteriores voltadas a dar suporte ao desenvolvimento econômico-industrial logrou alcançar grande parte de seus objetivos. O Brasil, ainda que marcado pelas deficiências sócio-políticas bem conhecidas, converteu-se no único país ao sul do Equador a possuir um parque industrial completo e moderno, posicionando-se entre as dez maiores economias do mundo. Este sucesso do nacional-desenvolvimentismo foi, todavia, obscurecido pelas transformações do cenário mundial nos anos 1980, bem como por suas repercussões internas. Mesmo assim, o modelo resistiu durante o primeiro governo pós-regime militar.

Com o encerramento do regime militar em 1985, a política externa da Nova República apresentou uma evolução singular. O Ministro Olavo Setúbal mostrou-se determinado a romper com a linha diplomática do Pragmatismo Responsável e do Universalismo. Argumentava que o Brasil era um país Ocidental, que deveria maximizar suas oportunidades individuais, em cooperação com os EUA, para chegar ao Primeiro Mundo. Obviamente sua ênfase foi no afastamento do Terceiro Mundo e de suas reivindicações. Sua política baseava-se em larga medida na situação internacional, caracterizada pela relativamente bem sucedida tentativa norte-americana de reafirmar sua liderança, pela crise e reforma do socialismo (a ascensão de Gorbatchev foi praticamente simultânea ao início da Nova República) e pelas crescentes dificuldades do Terceiro Mundo, pois em 1985, na Reunião de Cúpula do G-7 em Cancun, o diálogo Norte-Sul foi abandonado. Contudo, o Itamaraty resistiu 
a esta nova orientação, que se assemelhava à diplomacia de Castelo Branco. Assim, no início de 1986 o Chanceler era substituído por Abreu Sodré. Uma de suas primeiras medidas foi o reatamento de relações diplomáticas com Cuba, que fora até então obstaculizada por Setúbal e pelo Conselho de Segurança Nacional.

A cooperação com a URSS cresceu, especialmente com as esperanças despertadas pela Perestroika, mas logo a crise soviética e a convergência entre Moscou e Washington frustraram-na. Em relação à China, intensificou-se o comércio e desenvolveram-se projetos tecnológicos, especialmente na área espacial. Com relação ao Terceiro Mundo e aos organismos internacionais, Sarney conservou a mesma linha que iniciara com Geisel, mantendo atitudes que foram apoiadas até pela esquerda. Com relação à África, ao Oriente Médio, à Europa Ocidental e ao Japão, a política foi igual à de Figueiredo, só que marcada por maiores dificuldades. Também permaneceu inalterada a diplomacia centro-americana do Brasil, com apoio ativo ao Grupo de Contadora e crítica à atuação dos EUA.

Quanto mais se estreitavam as possibilidades de atuação do Brasil no plano global, mais a América do Sul foi valorizada como alternativa estratégica, tendo seu eixo centrado na cooperação e integração com a Argentina, com problemas semelhantes aos do Brasil. O retorno da democracia, com os presidentes Raúl Alfonsín e José Sarney, se deu numa conjuntura adversa do ponto de vista econômico e diplomático. A crise da dívida fez com que os países latino-americanos ficassem extremamente vulneráveis às pressões do FMI e do Banco Mundial, enquanto o conflito centro-americano permitia ao governo Reagan trazer a Guerra Fria para o âmbito hemisférico, o que lhe possibilitava também utilizar instrumentos diplomáticos e militares para exercer uma pressão suplementar sobre a América Latina. Os dois países haviam aderido ao Grupo de Apoio à Contadora.

Em 1985, através da Declaração de Iguaçu, foi estabelecida uma comissão para estudar a integração entre os dois países e em 1986 foi assinada a Ata para Integração e Cooperação Econômica, que previa a intensificação e diversificação das trocas comerciais. Fruto deste esforço, em 1988 foi firmado 
o Tratado de Integração, Cooperação e Desenvolvimento Brasil-Argentina, que previa o estabelecimento de um Mercado Comum entre os dois países num prazo de dez anos. O que estava por trás desta cooperação era a marginalização crescente da América Latina no sistema mundial, a tentativa de formular respostas diplomáticas comuns aos desafios internacionais, a complementação comercial, a criação de fluxos de desvio de comércio e um esforço conjunto no campo tecnológico (particularmente nuclear). Era o caminho que conduziria, em 1991, à criação do Mercosul.

A Globalização neoliberal marca a abertura de um novo período, que não será analisado nesse artigo, mas, no caso Brasileiro, ela é marcada pela alternância de uma adesão mais passiva (aceitação quase incondicional das regras) e de outra mais interativa (negociando e propondo). A primeira foi a marca da diplomacia das presidências Collor, Cardoso e Temer. A segunda foi a marca de Itamar Franco, Lula da Silva e Dilma Rousseff, cuja diplomacia se caracterizou por uma Continuidade sem Prioridade. O caso de Bolsonaro, de viés ideológico, marca uma ruptura com a tradição diplomática nacional, em um mundo dividido e em crise (agravado pela Pandemia Covid-19). A Globalização é, hoje, combatida por aqueles que a criaram, e o futuro nunca foi tão incerto, mas a História segue sendo ferramenta indispensável aos analistas de RI. (junho de 2020).

\section{Referências}

BANDEIRA, M. Presença dos Estados Unidos no Brasil. Rio de Janeiro; Civilização Brasileira, 1976.

CERVO, A.; BUENO, C. História da política exterior do Brasil. São Paulo: Ática, 1992.

MOURA, G. Autonomia na dependência. a política externa brasileira de 1935 a 1942. Rio de Janeiro: Nova Fronteira, 1980.

RODRIGUES, J. H. Interesse Nacional e Política Externa. Rio de Janeiro: Civilização Brasileira, 1966

RODRIGUES, J. H. Brasil e África, um novo horizonte. Rio de Janeiro: Civilização Brasileira, 1964. (2 vols.)

SILVA, J. L. W. da; GONÇALVES, W. Relações Internacionais do Brasil I (1808-1930): a diplomacia da agroexportação. Petrópolis: Vozes, 2009. 
Intelligere, Revista de História Intelectual

no 10 , dez.2020

VISENTINI, P. F. O Regime Militar e a projeção mundial do Brasil (19641985). São Paulo: Almedina/ Edições 70, 2020. 